\title{
AS CIÊNCIAS DA COMUNICAÇÃO NA FRANÇA
}

\author{
Autor: Luiz Renato Busato \\ Professor da Université Stendhal-Grenoble3 \\ Institut de la Communication et des Médias \\ Groupe de recherche sur les enjeux de la communication - GRESEC
}

\section{Apresentação}

Em dezembro de 2010 a Universidade Federal do Paraná homenageou a primeira turma do curso de pos graduação em comunicação social e, retomando a tradição de certas academias, ela organizou uma ultima aula. $\mathrm{O}$ assunto escolhido para essa ocasião tratou de historia da comunicação ; efetivamente, em sintonia com a direção do curso, pensamos que o estudante que conhece bem a historia da sua disciplina é o que tem as melhores chances de se manter atualizado quanto às evoluções cientificas e técnicas e quanto às suas praticas profissionais.

O lugar dessa historia não é o Brasil, mas a França, vista como uma das fontes inspiradoras da evolução nacional dos estudos de comunicação. A comunidade brasileira de comunicadores -profissionais de todas as áreas do ensino e da pesquisa, da comunicação social, do marketing comercial, político etc.- já se organizou ha muitas décadas com normas profissionais (éticas, técnicas, comerciais) e com praticas cientificas mescladas de especificidades brasileiras e de universalidade. De modo particular, ela sempre esteve atenta à dicotomia entre as tendências ditas dos cultural studies, de tradição anglo saxônica, e as ditas das Sciences de l'Information et de la Communication, ligadas à tradição euro-latina em geral e francesa em particular.

Este texto, extraído da aula de conclusão do curso mencionada acima, apresenta na primeira parte alguns tópicos da luta dos acadêmicos e outros profissionais franceses para dar uma ancoragem cientifica credível à comunicação ${ }^{1}$, e na segunda parte, afim de trazer uma

\footnotetext{
1 Não entraremos aqui nas distinções possiveis entre professores/pesquisadores/acadêmicos de um lado e profissionais de outro lado ; o que distinguimos neste texto é de ordem pratica, dado que todos os atores da comunicação que aqui nos interessam, inclusive os acadêmicos, são profissionais da area, e todos têm algo a ver com a economia e o mercado.
} 
demonstração à primeira, apresenta um quadro indicativo da produção cientifica sob a forma de teses de doutoramento apresentadas na França nos últimos quarenta anos.

Esta modesta incursão histórica leva em conta o fato que a construção do campo cientifico da comunicação deu-se num período curto e recente : muitos dos seus fundadores, tanto na França como no Brasil, são vivos e ativos ; esta situação típica constitui uma riqueza para o estudo da disciplina mas, por outro lado, ela impede o distanciamento temporal, decisivo quando se trata de fazer a triagem entre fatos principais e fatos secundários. Ela leva em conta igualmente os paralelismos notáveis entre as duas historias, brasileira e francesa, da comunicação, oriundos de uma interpenetração crescente das comunidades nacionais. Em consequiência as transações ocorridas entre os dois paises na área da comunicação são diferentes das que predominaram em outras épocas e em outras disciplinas. Nota-se, por exemplo, que ao longo dos anos de construção do campo cientifico, o Brasil nunca foi percebido pela comunidade francesa como um simples contribuinte acessório, eventualmente assistido (e às vezes colonizado), mas como um parceiro sério (conhecem-se algumas exceções, mas elas são também recíprocas). Desde os primeiros contatos assíduos entre as duas comunidades, a França integrou o Brasil nos seus mapas mentais e isso não se refere unicamente à sempre invocada diferença de porte geográfico ; trata-se, de fato, da competência brasileira para a produção teórica em quantidade e qualidade notáveis, de sua aptidão para aglutinar uma comunidade acadêmica numerosa e heterogênea, de suas capacidades, inclusive financeiras, para organizar dispositivos e produções editoriais de qualidade internacional, de sua inteligência para integrar a realidade social no campo da comunicação tanto quanto este campo na realidade social, à traves de pesquisas empíricas, etc. É claro que ha ainda muito que fazer para que as complexas situações nacionais sejam totalmente compartilhadas, mas o que já foi construído merece ser notado e preservado como base para o futuro das relações binacionais.

\section{A estruturação cientifica da comunicação na França}

Os tópicos que selecionamos para apresentar a situação da comunicação na França o foram tanto pela importância que tiveram na construção de uma aura cientifica para as SIC, quanto pelas suas semelhanças com a historia do mesmo campo comunicacional no Brasil.

1) As ciências da comunicação devem ser consideradas como uma ciência ou não ? 
A resposta mais convincente é : não se sabe com certeza !

Mas ha inúmeras correntes de pensamento e inúmeros pensadores que acham que é. Outros que acham que a discussão não acabou. Outros que consideram que a questão não tem sentido, pois que a pregnância da comunicação na esfera individual e social é tão grande que ela é suficiente para se discutir comunicação...

Essa variedade de respostas não é uma característica exclusiva das SIC, mas pode-se perguntar porque ela existe aqui também e de maneira tão radical. Uma hipótese de resposta reside na dificuldade para se determinar, de maneira clara e consensual, um "objeto" que seja especifico às SIC. Ora, essa condição é necessária para se enquadrar um campo qualquer na categoria de ciência. Para muitos autores, o que se da como objeto central da comunicação não passa de uma idéia, ou na melhor das hipóteses de uma noção, mas não de um real objeto de ciência : trata-se do termo de interação. Este serve para definir todos os objetos e formas de transação -quer sejam elas de ordem natural ou cultural- que os homens estabelecem entre si, ou com o mundo da natureza, ou com o mundo das técnicas. Alguns conteúdos de outras ordens são anexados por esta definição, tais como a idéia de mensagem, ela própria servindo para definir ora a existência de informações ${ }^{2}$, ora a de relações, ora a de ambas simultaneamente.

2) Excluindo-se esse objeto genérico chamado interação/informação/relação, o que encontramos é uma tendência profunda das SIC de englobar uma quantidade e uma variedade quase ilimitada de objetos, campos, atividades, profissões, técnicas... Essa profusão é incompatível com o rigor exigido de uma ciência. As SIC, entretanto continuam se apresentando como múltiplas, plurais e esfaceladas como se nota por exemplo na obra de Armand e Michele Mattelart : ... "campo cientifico que, historicamente, se inseriu entre as redes físicas" (transportes, telefone, estradas) "e imateriais" (escolas de pensamento mas também, mais recentemente, redes simbólicas no plano da economia, da política), “o biológico e o social, a natureza e a cultura, os dispositivos técnicos e os discursos, a economia e a cultura, as perspectivas micro e macro, a aldeia e o mundo, o ator e o sistema, o individuo e a sociedade" ${ }^{3}$...

\footnotetext{
${ }^{2}$ A noção de informação é essencial nesse contexto pois ela designa todo o trabalho humano de construção, deconstruçâo e reconstrução dos dados internos e externos à consciência, o que significa, fundamentalmente, que informar consiste em retratar os objetos para si mesmo e para a transmissão aos outros ; o mundo não se da na sua verdade integral à consciência, e esta não pode capta-lo sem passar por transformações que o tornem comunicável.

${ }^{3}$ Mattelart Armand, Mattelart Michele,1995, 5
} 
Num plano mais institucional do que o de pesquisadores isolados encontramos em 1993 outras duvidas radicais sobre o estatuto das SIC ; elas provém do Conselho Nacional de Avaliação (CNE), organismo ministerial encarregado de avaliar a oferta cientifica das universidades ; para ele as SIC constituem um conjunto plural, pouco nítido, cujos contornos são zonas de contado, interfaces, lugares movediços de trocas entre atores disparates de dados, conteúdos, símbolos, informações... muito mais do que como fronteiras nítidas em relação às outras disciplinas ou ciências.

Esta composição pletorica levou muitos pensadores ${ }^{4}$ a definir as SIC, desde 1975, não como uma disciplina cientifica autônoma, mas como uma inter-disciplina ; o que pode não ser contraditório tendo-se em vista a natureza dos domínios das ciências humanas e sociais em que as transversalidades -ou interdisciplinaridades- são freqüentes.

3) Apesar das dificuldades ainda hoje muito persistentes para se encontrar uma definição satisfatória de comunicação, a corporação nascente de comunicadores conseguiu manter um consenso mínimo sobre o seu próprio dissenso, e fazer coabitar, bem ou mal, pesquisadores, correntes teóricas, disciplinas, instituições... Mediante isso ela poude continuar a sua caminhada histórica para se impor como atora central no campo da mídia e, mais amplamente, no campo das ciências humanas e sociais ${ }^{5}$. Foi assim que emergiram estruturas burocráticas de regulação como a secção 71 do Conselho Nacional das Universidades, as comissões de recrutamento, etc. ; foi também assim que as SIC conseguiram dotar-se de alguns dos atributos "indispensáveis" para torna-las visíveis pelas instituições burocráticas em geral e pelas outras ciências em particular ; entre esses atributos esta a mítica postura de luta pela cientificidade, seguida de uma luta igualmente rude para estabelecer a sua imperiosa necessidade na promoção do progresso, da democracia, da igualdade social..., ela mesma seguida pela luta final que constitui a criação de uma identidade profissional positiva dos atores que entram nesse novo espaço de pensamento e de açâo. Essas conquistas localizadas permitiram de manter (ou dar a ilusão de manter) uma certa unidade (pois que não se pode falar de unicidade) de todos os objetos dispares mencionadas acima ${ }^{6}$.

\footnotetext{
${ }^{4}$ D'entre eles Bernard Miège particularmente, ator central do desenvolvimento das SIC na França e criador da escola de pensamento comunicacional dita "escola de Grenoble".

${ }^{5} \mathrm{O}$ consenso é raro também neste ultimo aspecto : deve-se incluir as SIC no campo das ciências humanas ? ou no campo das sociais ? ou nos dois ? Solução imaginativa de certos autores é que as SIC constituem as novas humanidades, espécie de substituto da filosofia como matriz de todo pensamento humano.

${ }^{6}$ Boure Robert, 2002, p. 36.
} 
$\mathrm{Na}$ tarefa de atribuição dos méritos por tal ou tal dessas conquistas (o que não é o projeto desse texto), encontraríamos em primeira linha a determinação e até mesmo a obsessão de lideres acadêmicos ou de promotores sociais (educadores, animadores sociais, artistas, fornecedores de produtos, programas e serviços de comunicação), mas também encontraríamos fatores ligados de ordem política, ou da ordem dos determinismos sociais, tecnológicos, financeiros, culturais... que se impõem a todos esses atores ${ }^{7}$.

4) Uma das consequiências dessas evoluções é que, à medida em que se ampliavam os espaços ocupados pela comunicação, se construíam os elementos de identidade sócioprofissional de todos aqueles protagonistas ${ }^{8}$. Efetivamente, com o passar dos anos, cada "novo integrante" da comunidade dos comunicadores vai fazer muita conta das representações simbólicas que lhe permitirão de se elevar ao nível dessa ciência nova, moderna, ao mesmo tempo em que ele se investe para que a novidade se consolide, se estenda e se banalize na esfera social. Cada novo entrante vai, à sua maneira, atravessar um processo de iniciação à nova ciência, e traçar as suas rotas profissionais entre opções múltiplas que poucas ciências sociais e humanas tiveram : pesquisa teórica, pesquisa aplicada, transmissão pedagógica dos novos conhecimentos, consultoria política, social, industrial, intervenção associativa, criação, concepção, realização ou promoção de programas, de produtos ou de mídias... Nos últimos cinqüenta anos as possibilidades profissionais dentro da área da comunicação parecem ilimitadas, dado que essa ciência, na pratica, é assimilada a todas as profissões que implicam mais de duas pessoas... E ha cada vez mais pesquisas estudando a comunicação pessoal através, por exemplo, das maquinas e dispositivos de auto-comunicação como as agendas eletrônicas, a musica nômade, et muitos outros objetos de uso individual.

Até os anos 90 a grande maioria dos membros afiliados ou próximos das SIC provinham de outros campos científicos mais ou menos distantes da comunicação, e essa exterioridade é ainda hoje sentida como um fator de enriquecimento da área. Omitem-se nesse caso os ajustamentos de identidade cientifica e corporativa que foram necessários à maioria

\footnotetext{
${ }^{7}$ A maneira dos "fatos sociais" definidos em sociologia por Augusto Comte ou Emile Durkheim.

${ }^{8}$ Identidade pessoal e institucional povoada de mitos e de personagens fundadores, de sociedades, academias, comissões cientificas ou disciplinares novas, de funções oficiais dadas a comunicólogos na direção de universidades ou faculdades, em instancias nacionais e internacionais de "expertise", em gabinetes ministeriais, em consultorias para a grande mídia, as empresas, os homens políticos e os partidos... Sem contar a implementação de dispositivos típicos da pratica cientifica tais que coleções de livros, organização de colóquios nacionais e internacionais, a criação de revistas, circulação internacional de professores e pesquisadores que encontram por toda parte -a Europa e as Américas, mas também a Ásia, a África, os paises da Europa oriental- o mesmo entusiasmo frente à novidade comunicacional.
} 
dos comunicadores da época ; pessoas que nos anos 60 ou 70 chegavam ao campo da comunicação vindos da filosofia, da sociologia, da historia, da economia, das letras ou do jornalismo se perguntavam seriamente aonde é que essa "novidade" iria conduzi-los. As duvidas atenuaram-se a partir dos anos 90 porque o campo adquiria seus direitos de cidadania a través de inúmeros sinais de legitimidade como o foi, por exemplo, a criação de currículos específicos no ensino médio e no ensino superior. Essa nova modalidade de reprodução corporativa era baseada, tanto no Brasil como na França, numa formação acadêmica quase que mono disciplinar, em que a comunicação social servia de heliotropo (área de concentração) para variantes curriculares inspiradas mais pela carta de profissões, que se ampliava ano apos ano, do que pelas áreas de especulação humanística das ciências sociais e humanas tradicionais. A partir da criação dos diplomas de comunicação nos anos 80 e até os anos 2000 apareceram novas interrogações identitarias como esta : será mesmo que o mundo pode ser pensado (em todo caso academicamente) unicamente através as lentes das SIC ...? Ao coloca-la, muitos dos novos integrantes das SIC sentiam-se invadidos por um vazio existencial que o volume crescente de publicações sobre comunicação não conseguia preencher. Não aprofundamos as investigações para saber se esta fase foi provisória, nem para saber se os profissionais da era do tudo-digital se questionam sobre sua identidade nem em que termos eles os fariam.

5) O que era definido como o campo das SIC nos idos dos anos 60 -comunicação de massa, meios e técnicas de comunicação -totalmente analógicos e funcionando segundo a lógica da difusão emissor-receptor ${ }^{9}$ - é hoje açambarcado pela mídia analógica ; essa mutação em si considerável não modificou fundamentalmente os questionamentos relativos à natureza cientifica da comunicação ; pelo contrario, constata-se que as duvidas sobrevivem.

Uma razão fundamental para essas duvidas esta no fato, conhecido, que as SIC não têm os privilégios das ciências exatas, que são a capacidade de descrever os objetos objetivamente, de produzir leis que autorizam a repetição e a previsão, de separar, através de métodos adaptados, o observador e os objetos observados ${ }^{10}$. No caso das SHS não dispomos

\footnotetext{
${ }^{9}$ Preferimos excluir aqui os campos da comunicação interpessoal, que estava na época ligada à pedagogia e à psicologia social (dois campos disciplinares que continuam sofrendo duvidas quanto aos seus estatutos científicos), porque as dominantes comunicacionais da época estavam estreitamente ligadas ao desenvolvimento tecnológico das maquinas e ideológico dos novos poderes da palavra no espaço publico.

${ }^{10}$ Considera-se que a reflexão sobre comunicação humana (comunicologia) deve começar pela invenção da escrita e pela retórica, mas que a reflexão cientifica tem suas origens bem próximas das ciências exatas, e cita-se regularmente os aportes significativos de uma plêiade de experimentadores, engenheiros, lingüistas como John Pierce, Claude Shannon, Norbert Wiener ... para sustentar a gênese cientifica da comunicação. Mas essas cartas
} 
dessas certezas... Os objetos estão em movimento constante, a previsibilidade se reduz a tempos e circunstancias variáveis, a veracidade depende tanto ou mais de resultados funcionais da maquina, da ação, objetivos e interpretações dos atores, do que de características substanciais ...

Ha outras questões que comprometem um hipotético consenso sobre o estatuto cientifico das SIC. E o caso de seus regimes de historicidade ${ }^{11}$, de suas epistemologias, de suas metodologias. Não vamos trata-las aqui, mas somente lembrar que uma delas tem um peso determinante para validar o estatuto cientifico : é a questão do método ; toda ciência deve gerar seus próprios métodos para explorar os seus próprios objetos.

Como já vimos, a expressão "métodos próprios" é imprópria, porque, em geral, os campos de investigação das SIC são tratados com o socorro de outras ciências. Por exemplo, a questão do "publico" (e por extensão dos "usos" que ele faz da informação, da comunicação, dos suportes midiaticos) foi fundadora da sociologia positiva com Weber, Le Bon e mais precisamente com Gabriel Tarde, que lhe definiram os contornos. A psicologia social contemporânea da sociologia nesse ponto- também tratou do assunto. A sociologia, por sua vez, estabeleceu os grandes eixos da comunicação política, assumida depois pelas ciências políticas. A economia apreendeu (com Marx, com os representantes da Escola de Francfort entre outros) as questões da oferta e da demanda de produtos materiais e imateriais de comunicação, mas também de programas e conteúdos. A psicologia estabeleceu paradigmas de comunicação inter-pessoal em aspectos básicos como os de motivação, desejo, expectativa. As ciências da educação se ampararam desde cedo das questões de aprendizagem e mais recentemente das questões cognitivas. Da mesma forma, as SIC herdaram de métodos e de alguns paradigmas em áreas como a informática e as neurociências. E assim por diante ... Essa lista não exaustiva dos empréstimos metodológicos feitos pelas SIC não significa que as SIC sejam estéreis ; elas geraram, e continuam gerando métodos e resultados em alguns setores tais como o estudo de suportes e programas midiaticos, genealogia e natureza dos objetos técnicos de comunicação, em questões ligadas à imprensa e ao jornalismo e, mais recentemente, nos campos do multimídia, do celular e outros objetos nômades de

de nobreza cientifica não resistiram para além dos anos 70, em que as exceções à regra representavam segmentações específicas, como o das telecomunicações, mas que não reclamam uma inscrição necessária no campo das SIC.

${ }^{11}$ Uma delas é precisamente a historia das fronteiras da disciplina. Ela emerge, por exemplo, no projeto de posicionamento da sociedade francesa SFSIC (Société Française des Sciences de l'Information et de la Communication), que escrevia em 1997 (portanto vinte anos depois de sua constituição como sociedade cientifica nacional) : "Se os debates sobre o estado e a legitimidade das SIC existem na nossa interdisciplina, eles não impedem a ela de existir socialmente" 
comunicação, dos estudos de opinião publica... Entretanto as novidades cientificas consistentes geradas unicamente pelos recursos metodológicos das SIC são inversamente proporcionais às novidades geradas com a ajuda de outras ciências.

Duas observações suplementares nos parecem úteis no que concerne esta outra questão central relativa às SIC que é a da sua historia. A primeira consiste em lembrar que o próprio termo de SIC foi, na França, um compromisso quase "comunicacional" ; efetivamente, os atores fundadores hesitaram entre as denominações de "ciências das representações", "ciências das significações", ou "ciências da comunicação", "humanidades", ${ }^{2}$ etc... Finalmente foi a sigla SIC que ganhou para conciliar um maior numero de especialistas das áreas que reivindicavam pertencer aos campos da informação (jornalistas, documentaristas) e ao da comunicação (comunicólogos, consultores em comunicação institucional ou empresarial).

Essa denominação teve um efeito estruturante que perdura até hoje (de maneira dura justamente pois que ela não deixa espaço para outras etiquetas), pois ela associa substancialmente as duas áreas, tanto do ponto de vista epistemológico como do ponto de vista pratico ; alguns autores se esforçam para operar distinções substanciais mas com pouco sucesso até hoje. Essa é uma das particularidades da disciplina na França, pouco em uso na maioria dos outros paises. No Brasil essa dicotomia tem mais um caráter retórico do que cientifico. $^{13}$

A segunda observação visa a lembrar a importância em se escolher a modalidade de conto histórico para as SIC, se ele deve ser de tipo cronológico ou retrospectivo. O primeiro que tende à objetivar o passado a partir dos dados do passado, o que implica um esforço de retorno ao ambiente do passado ; o segundo que tende a ver o passado a partir do presente. Nos dois casos corre-se o risco de mistificar ou de cloroformizar o passado e de instrumentalizar o presente ${ }^{14}$.

Para um estudante atual de comunicação esses questionamentos podem ter um interesse particular : o de salva-lo do heliocentrismo comunicacional. Constata-se, na França mas quem sabe também no Brasil, que a falta de consciência dos limites inerentes à comunicação (quer seja ela tratada como ciência quer como uma disciplina ou uma pratica

\footnotetext{
${ }^{12}$ Robert Boure, op.cit.

${ }^{13} \mathrm{Um}$ dos textos recentes que pode ilustrar essa diferença entre a França e o Brasil é a tese de José Ricardo da Silveira, O jornalista na comunicação das organizações : cultura profissional e autopercepçâo, defendida na UnB em dezembro 2010.

${ }^{14}$ NOBLET Arnaud, Lês regimes d'historicité du journalisme - Héritages et transformations à l'ère d'Internet, Tese de doutoramento defendida em Lyon, dezembro 2010.
} 
social), pode conduzir, pouco a pouco, o jovem profissional a se despojar das virtudes desse mesmo campo e de guardar somente um lote de reflexos tecnicistas que, no melhor dos casos, fará dele um profissional medíocre, e no pior, um individuo frustrado ou deprimido.

\section{O estado da pesquisa em comunicação na França pelo prisma das teses de doutoramento}

Uma de atividades matriciais das SIC são, naturalmente, as teses apresentadas por doutorandos e pós-doutorados. Nesta segunda parte vamos sintetizar num quadro e em alguns comentários a produção francêsa desde o final dos anos 70 até hoje.

Ha, naturalmente, outros enfoques possíveis, e com certeza muito férteis, para estabelecer um mapa das SIC. Percorremos alguns deles (colóquios, congressos, eventos científicos, atividades editoriais, currículos das universidades que fazem ofertas na área das SIC, políticas cientificas quando elas atravessam as áreas das SIC -legislações, financiamentos prioritários, iniciativas governamentais em direção dos atores midiaticos ou da sociedade em geral- antes de optar pelo enfoque doutoral.

A base de dados utilizada para o estudo das teses foi o SUDOC, no endereço web http://www.abes.fr/abes/page,407,z39.50.html. Essa base recebeu por missão de racionalizar a documentação sobre as teses a nível nacional, e, apesar de ela ser recente (final de 2010), já permite uma boa apreensão do panorama cientifico.

Apresentamos os resultados do estudo por meio de um quadro sintético que uma leitura atenta pode tanto dispensar de comentários como suscitar tantos que eles poderiam ser escolhidos como... assunto de tese.

A metodologia do estudo consistiu em :

a. selecionar uma fonte fiável e, tanto quanto possível completa, de indexação das teses ;

b. notar melodicamente e sistematicamente esta base, guardando para cada série de informações as mesmas formulas de consulta ;

c. selecionar entradas temáticas em função de uma lista estabelecida previamente, englobando a maior parte das temáticas correntes escolhidas pelos doutorandos e diretores de teses. Retivemos 37 temáticas, cujo enunciado serviu de entrada para a busca no interior da base SUDOC ; outras explorações, com outras terminologias isoladas ou 
associadas, dão resultados novos mas em pequena quantidade ; a maioria destes retoma, de fato, termos de indexação superiores incluídos nas 37 temáticas selecionadas ;

d. estabelecer um plano temporal para as consultas preparatórias da base foram (entre agosto e novembro de 2010), e para a extração final das informações (realizadas num período curto de dez dias afim de reduzir ao mínimo as distorções temporais tais como acréscimos, supressões -aparentemente raras-, modificações de formulação das temáticas, etc).

\section{TEMÁTICA DEFENDIDAS EM TESES NA FRANCA ENTRE 1960 E $2010^{15}$}

Fonte : Base de dados SUDOC (consultas feitas entre 22/11/2010 e 30/11 2010) Observação : Não traduzimos os enunciados temáticos esperando que os recursos de intercompreençâo lingüística do leitor são suficientes para a interpretaçâo

\begin{tabular}{|c|c|c|c|c|c|c|c|}
\hline & & $\begin{array}{l}\frac{0}{5} \\
\frac{1}{1} \\
8 \\
2\end{array}$ & $\frac{8}{\infty}$ & $\frac{8}{\frac{8}{1}}$ & $\begin{array}{l}8 \\
8 \\
\frac{1}{1} \\
\text { gे }\end{array}$ & 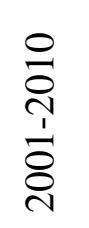 & 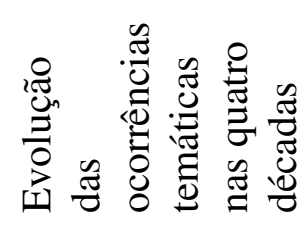 \\
\hline & Numero de teses & & 116 & 169 & 287 & 715 & 6,1 vezes \\
\hline 1. & Communication sociale & & & 2 & 4 & 35 & $17,5 \mathrm{x}$ \\
\hline 2. & Communication et médias & & & 2 & 15 & 52 & $26 x$ \\
\hline 3. & Communication de masse & & & 3 & 3 & 20 & $6 x$ \\
\hline 4. & Communication et radio & & & 4 & 3 & 12 & $3 x$ \\
\hline 5. & Communication et télévision & & & 2 & 15 & 16 & $8 x$ \\
\hline 6. & Communication et internet & & & & 11 & 50 & $4,5 \mathrm{x}$ \\
\hline 7. & Communication d'entreprise & & & 3 & 16 & 54 & $18 \mathrm{x}$ \\
\hline 8. & Communication des organisations & & & 1 & 13 & 52 & $52 x$ \\
\hline 9. & Communication publicitaire & & & & 4 & 3 & $-0,75 x$ \\
\hline 10. & Communication et marketing & & & & 5 & 6 & 1,2 \\
\hline 11. & Communication institutionnelle & & & 1 & 11 & 48 & 48 \\
\hline 12. & Communication politique & & & 5 & 25 & 52 & $10,4 \mathrm{x}$ \\
\hline 13. & Communication internationale & & & & 1 & 5 & $5 x$ \\
\hline 14. & Communication locale & & & 1 & 3 & 3 & $3 x$ \\
\hline 15. & Communication territoriale & & & & 1 & 1 & $0 \mathrm{x}$ \\
\hline 16. & Communication et société & & & & 7 & 25 & $3,5 \mathrm{x}$ \\
\hline 17. & Communication et éducation & & & & 7 & 40 & 5,7 \\
\hline 18. & Communication populaire & & 1 & 2 & & 7 & $7 x$ \\
\hline 19. & Communication et journalisme & & & 6 & 15 & 21 & $3,5 \mathrm{x}$ \\
\hline 20. & Communication et développement & & 1 & & 14 & 32 & $32 x$ \\
\hline
\end{tabular}

${ }^{15}$ Numero de teses defendidas entre 1970 et 2010 por universidade :

Paris : 375, Bordeaux : 172, Rhône : 117, Aix-Marseille : 108, Isère : 102, Nanterre : 68, Lille : 46, Montpellier : 41, Toulouse : 40, Rennes : 28, Dijon : 22, Nancy-Metz: 21, Avignon : 18, Strasbourg : 18, Créteil : 5 , Nice : 5 . 


\begin{tabular}{|l|l|l|l|l|l|l|l|}
\hline 21. & Communication et nouvelles technologies & & & & 8 & 96 & $12 \mathrm{x}$ \\
\hline 22. & Communication et santé & & & & & 7 & - \\
\hline 23. & Communication et banlieues & & & & & 1 & - \\
\hline 24. & Communication et culture & & & 4 & 7 & 34 & $8,5 \mathrm{x}$ \\
\hline 25. & Communication et arts & & & & 2 & 7 & $3,5 \mathrm{x}$ \\
\hline 26. & Communication et linguistique & & & & 2 & 2 & 0 \\
\hline 27. & Communication et langues & & 1 & 2 & 21 & 38 & $38 \mathrm{x}$ \\
\hline 28. & Communication et technique & & & & & 5 & - \\
\hline 29. & Communication et écologie & & & 3 & 4 & 14 & $4,6 \mathrm{x}$ \\
\hline 30. & Communication et économie & & 107 & 143 & 171 & 53 & $-2 \mathrm{x}$ \\
\hline 31. & Communication et sciences & & & & & 2 & - \\
\hline 32. & Communication et usages & & 107 & 147 & 181 & 177 & $1,65 \mathrm{x}$ \\
\hline 33. & Communication et information & & & & & 2 & - \\
\hline 34. & Communication et technologies éducatives & & & & 1 & & - \\
\hline 35. & Communication et minorités & & & 1 & 18 & 28 & $28 \mathrm{x}$ \\
\hline 36. & Communication et documentation & & & 1 & 2 & 6 & $6 \mathrm{x}$ \\
\hline 37. & Communication et environnement & & & & & & \\
\hline 38. & & & & & & & \\
\hline 39. & & & & & \\
\hline
\end{tabular}

Para uma leitura mais extensa desse quadro (o que não é possível no contexto desse artigo), é útil fazer alguns comentários para facilitar a leitura.

a) Os totais da primeira linha, que indicam o numero total de teses defendidas em cada período, não coincidem necessariamente com a soma que se pode fazer em cada coluna pois que, por um lado, a soma inclui temas ausentes da lista selecionada, e por outro lado há um certo numero de teses que estão indexadas em duas, três ou mais entradas.

b) As primeiras teses foram defendidas na década de 70 a 80 e são indexadas no tema comunicação e ciências ; no final da década, aparecem outras teses sob o tema comunicação e técnicas e comunicação e informação. (Pour une épiphanie des signes, de Guy Croussy, em Lille III.), e em 1980 aparece já uma tese defendida pelo brasileiro Sérgio Caparelli, intitulada "La télévision brésilienne et son modele de devéloppement".

c) Durante a década de 70 à 80 as pesquisas em SIC crescem, centradas em temáticas ligadas a setores técnicos e profissionais, novos ou mais antigos ; esses setores assumiam um peso importante na sociedade ; essa mesma década vive uma expansão notável da mídia de massa que, existente desde os anos 50 mas sem interessar muitos pensadores, começa nos anos 70 a ocupar um espaço cada vez maior tanto do ponto de vista da oferta quanto do ponto de vista da demanda social, política e institucional. Os estados implementam mecanismos novos de regulação apos duas décadas de empirismo, de experiências mais ou menos sucedidas, de programas herdados do mundo do teatro clássico ou popular, do filme popular, 
já instalado há mais de cinqüenta anos nas salas de projeção, mas que começa aqui uma nova carreira na esfera da pequena tela familiar ; nesse período se formam ou se consolidam os grandes grupos midiaticos e as sociedades de produtoras de programas.

No que toca à demanda, estamos nos anos 70 a 80 no final de um período que se chamou na França "Os trinta gloriosos", isto é : os trinta anos de desenvolvimento que levantaram o pais do desastre da segunda guerra mundial ; assim, as famílias tinham sede de desfrutar da modernidade, de importa-la para dentro de casa. O primeiro choque do petróleo em 1973 veio baixar temporariamente o entusiasmo desse período mas seus efeitos vão continuar ascendentes apesar da sucessão de outros choques petroleiros, dos contrachoques da descolonização (africana sobretudo), e da emergência das primeiras grandes ações terroristas em que a mídia sempre teve um papel central. O desejo do publico de participar da vida política, mas também de usufruir de lazeres relativamente baratos (disco, televisão, revistas em particular) não esmoreceu completamente com as crises sucessivas.

d) A verdadeira década de decolagem das SIC é a dos anos 80 a 90 . O numero de teses passou de 116 para 169 (68,6\%) ; nesse mesmo período nota-se um aumento considerável das temáticas inscritas em nome das SIC : havia 5 entre 70 e 80 e 18 na década seguinte, ou seja : doze temas novos integraram o campo, enquanto os temas "comunicação e ciência" e “comunicação e informação" permanecem majoritários como na década anterior (+ 72 \% e mais $74,8 \%$ respectivamente).

e) A década de 90 confirma o crescimento anterior e marca a consolidação do setor. $\mathrm{O}$ numero de teses aumenta de 58,8\%, outros temas novos integram o campo e são tratados por um numero bem maior de teses do que as do período anterior.

f) Na década de 2000 à 2010 o numero de teses aumenta de quase três vezes. Como na década precedente, o numero de temas aumentou e o numero de teses apresentadas em cada temática particular também aumentou sensivelmente.

g) Durante todo o período estudado o numero de teses defendidas baixou em quatro temas : comunicação publicitária (de 4 para 3), da comunicação lingüística (de 3 para 2), comunicação e ciências (de 171 para 53), comunicação e informação (de 181 à 177). Quanto aos temas constantes, eles são igualmente pouco numerosos e relativos à um baixo numero de teses que lhes haviam sido dedicadas ; são eles : comunicação local, comunicação territorial, comunicação e línguas.

Esta ultima observação não é tão significativa se enfocarmos unicamente os critérios quantitativos, mas ela se torna muito expressiva se adotarmos um enfoque histórico : ele 
indica que o crescimento da disciplina praticamente não encontrou obstáculos na sua trajetória. Os pontos de redução de atividade são pouco numerosos e não tocam no cerne da disciplina.

Um estudo mais aprofundado poderia testar a hipótese que as temáticas em baixa constituem setores que perdem importância. Da mesma forma seria útil desenvolver mais estudos sobre o significado da explosão e da permanência no tempo de certos temas claramente visíveis nos números das ultimas duas décadas.

Da mesma maneira podem levantar-se hipóteses sobre o interesse dos pesquisadores atuais do campo das SIC em estudar temáticas ou mídias tradicionais dada a abundância de pesquisas ligadas ao Internet, aos aparelhos nômades, miniaturizados, concentradores de conteúdos... Por enquanto o que aparece é que a pratica da comunicação (institucional, organizacional, corporativa, política, associativa...) não vai esmorecer pois que ela acedeu ao estatuto de setor estratégico, e portanto prioritário em todas as democracias antigas ou recentes ; em consequiência temáticas como comunicação e novas tecnologias, jornalismo, economia, cultura e até desenvolvimento continuarão a ocupar as atenções dos pesquisadores nos próximos anos.

Mas esse exercício prospectivo não tem embasamento cientifico sólido, pois são impressões fundadas em analises de contexto e de historia da mídia. E dizendo isso voltamos à questão inicial que é a de saber se a disciplina da comunicação tem futuro como ciência, mesmo se for ciência humana e social... Cada vez que uma nova disciplina ou ciência emerge no espaço intelectual e social há uma curva ascendente de interesse do publico e dos cientistas, interesse que baixa sistematicamente (com poucas exceções) num tempo difícil de determinar a priori.

Nota-se também que as boas idéias novas têm freqüentemente dificuldade de imporse, mas as que se impõem têm chances de atrair alguns bons cientistas durante períodos longos porquanto estejam ligadas a questões ou questionamentos fundamentais, de natureza epistemológica, teórica, histórica ou a mutaçôes sociais importantes.

\section{Conclusão}

No inicio dos anos 2000 se apontavam ainda varias dificuldades ou fragilidades à SIC na França, como o descreve Jean Meyriat ${ }^{16}$ : abertura internacional reduzida, uma legitimação

\footnotetext{
${ }^{16}$ In Boure, p. 68
} 
social apenas começada, uma pesquisa mal estruturada nacionalmente, uma consciência das implicações que não é ainda partilhada pelo conjunto da comunidade acadêmica.

Hoje pode-se dizer que essas fragilidades estão desaparecendo de maneira sensível, com uma ampliação dos intercâmbios internacionais, com a pesquisa bem estruturada nacionalmente via agrupamentos regionais de centros e equipes, uma amplificação da consciência que têm os jovens pesquisadores e profissionais do papel da comunicação na sociedade.

Mas, em contrapartida, novas fragilidades aparecem. Por exemplo : apos uma luta longa para institucionalizar o campo, fruto de muitas dissensões e poucos compromissos entre os promotores iniciais, existe o perigo de se ver, hoje, um fechamento esclerozante do campo sobre si mesmo, e, ao mesmo tempo, um efeito dispersivo pois que os guardiões do templo não podem continuar indefinidamente a comandar, pressionar, organizar. Estamos numa fase rica de idéias mas ainda incapaz de responder à questão fundamental do estatuto cientifico das SIC. Efetivamente, que ciência é essa que não gera regularidades métricas, como as ciências exatas ? Qual é sua abordagem epistemológica ideal quando há tantas possíveis ? Que consistência tem esse modelo francês face ao modelo dominante no mundo que é o anglo saxão com seus eixos "cultural studies" mais englobantes, menos fechados do que os SIC ? Que coerência existe entre as formações ditas de pesquisa, que implicam, concretamente, menos de $5 \%$ dos estudantes de comunicação, enquanto que os $95 \%$ outros se orientam para empregos de tipo técnico ou engenheiristico ? Como fazer com que os conhecimentos adquiridos pela pesquisa integrem os que se adquirem pela experiência pedagógica ou pratica e inversamente?

Essas questões e tantas outras ficam aqui abertas, com essa conclusão : desde os anos 70 somos testemunhos da emergência se não de uma nova ciência, pelo menos de uma disciplina que tem verdadeiros objetos, enfoques específicos, alguns métodos próprios, uma historia que começa a se densificar e, sobretudo, um real conteúdo social pois que a comunicação parece não ser nem contornável nem reversível. Da mesma forma é difícil pensar hoje sociedades sem mídia, sem mediações, sem mediadores, apesar de que menos de metade da humanidade vive em sociedades de "abundância comunicacional"17. E comunicação representa, para todas elas, não so uma aspiração individual de melhoria de vida, mas um critério de desenvolvimento inscrito em todas as grandes instancias

\footnotetext{
17 A expressão data dos anos 70 quando algums fundadores dos estudos de comunicação na França, como Abraham Moles, Edgard Morin, Robert Escarpit entreviam a explosão da comunicação (titulo de um livro de Philippe Breton e Serge Proulx) e previam suas conseqüências, bem evidentes hoje em dia, que são a abundancia da comunicação nos paises e populações mais abastados e sua carência nos mais pobres.
} 
REVISTA AÇÃOMIDIÁTICA - Estudos em Comunicação, Sociedade e Cultura Universidade Federal do Paraná

Programa de Pós Graduação em Comunicação Vol I. № 1. Ano 2011

internacionais. Fora das esferas cientificas, a comunicação continua a irrigar as sociedades e os indivíduos. 